\title{
PENGABDIAN MASYARAKAT PENDIDIKAN KESEHATAN MENJAGA KESEHATAN DAN KEBUGARAN MELALUI OLAHRAGA BAGI LANSIA DI POSYANDU EKA HARAPAN KELURAHAN PAHANDUT PALANGKA RAYA
}

\author{
Putria Carolina ${ }^{1}$, Yelstria Ulina Tarigan ${ }^{1}$, Bella Novita $^{2}$, Desi Indrini ${ }^{2}$, \\ Efriadi $^{2}$, Enteng Pandi Yangan ${ }^{2}$, Mendi $^{2}$, Marsiane Afiana ${ }^{2}$ \\ ${ }^{1}$ Dosen Program Studi Sarjana Keperawatan \\ ${ }^{2}$ Mahasiswa Program Studi Sarjana Keperawatan \\ Sekolah Tinggi Ilmu Kesehatan Eka Harap Palangka Raya \\ Email: putria ekaharap@yahoo.co.id
}

\begin{abstract}
ABSTRAK
LATAR BELAKANG. Lanjut usia adalah dimana seseorang mengalami pertambahan umur dengan disertai dengan penurunan fungsi fisik yang ditandai dengan penurunan massa otot serta kekuatannya, laju denyut jantung maksimal, peningkatan lemak tubuh, dan penurunan fungsi otak. Saat lanjut usia tubuh tidak akan mengalami perkembangan lagi sehingga tidak ada peningkatan kualitas fisik. Pada usia lanjut seseorang menderita penyakit tertentu namun tak berarti tidak boleh berolahraga. Olahraga bermanfaat untuk kesehatan jasmani maupun rohani. Manfaat olahraga diantaranya melancarkan sirkulasi darah, memperkuat otot, mencegah pengeroposan tulang, menurunkan tekanan darah, menurunkan kolesterol jahat, dan menaikkan kolesterol baik. Olahraga juga bermanfaat untuk membakar kalori, meningkatkan keseimbangan dan koordinasi otot, bahkan olahraga juga dapat meningkatkan kekebalan tubuh. Sedangkan manfaat lain olahraga adalah biasanya dapat menghilangkan sembelit, membuat tidur lebih nyenyak, serta mengurangi depresi.

METODE. Metode pelaksanaan kegiatan adalah dengan menggunakan strategi pendidikan kesehatan bagi kelompok lansia di Posyandu Eka Harapan Kelurahan Pahandut Palangka Raya.

HASIL. Kegiatan dilaksanakan dengan memberikan pendidikan kesehatan dengan metode ceramah dan tanya jawab. Media pendidikan kesehatan yang digunakan adalah dengan LCD proyektor dan leaflet yang dibagikan kepada lansia serta melaksanakan senam kebugaran lansia. Materi yang diberikan adalah mengenai pentingnya menjaga kesehatan dan kebugaran melalui olah raga. Selama kegiata berjalan, lingkungan kondusif, lansia antusias mendengarkan dan aktif bertanya saat diberikan kesempatan untuk diskusi. Hasil evaluasi pendidikan kesehatan menunjukkan lansia mampu untuk menyebutkan dan menjelaskan kembali mengenai pentingnya menjaga kesehatan.

KESIMPULAN. Kegiatan pengabdian masyarakat yang dilakukan oleh dosen, dan mahasiswa kepada lansia dapat dinyatakan berhasil. Melalui hasil evaluasi selama pendidikan kesehatan berlangsung yaitu adanya respon yang positif dari lansia dan juga mampu untuk menyebutkan kembali mengenai materi yang telah dipaparkan.
\end{abstract}

Kata Kunci: Pendidikan Kesehatan, Lansia, Kebugaran 
Pengabdian Masyarakat Pendidikan Kesehatan Menjaga Kesehatan Dan Kebugaran Melalui Olahraga Bagi Lansia Di Posyandu Eka Harapan Kelurahan Pahandut Palangka

Raya

\section{ABSTRACT}

BACKGROUND. Elderly is a person experiences age growth accompanied by a decrease in physical function characterized by a decrease in muscle mass and strength, a maximum heart rate, an increase in body fat, and a decrease in brain function. As you get older your body will not experience development again so there is no increase in physical quality. In old age a person suffers from a certain disease but does not mean that he should not exercise. Exercise is beneficial for physical and spiritual health. The benefits of exercise include promoting blood circulation, strengthening muscles, preventing bone loss, lowering blood pressure, lowering bad cholesterol, and raising good cholesterol. Exercise is also beneficial for burning calories, improving muscle balance and coordination, and even exercise can boost immunity. While other benefits of exercise are usually able to eliminate constipation, make sleep better, and reduce depression.

METHOD. The method of implementing the activity is to use a health education strategy for the elderly group at Posyandu Lansia Eka Harapan Kelurahan Pahandut Kota Palangka Raya.

RESULTS. The activity was carried out by providing health education with lecture and question methods. The health education media used are LCD projectors and leaflets distributed to the elderly and carrying out elderly fitness exercises. The material provided is about the importance of maintaining health and fitness through exercise. As long as the activities are running, the environment is conducive, the elderly are enthusiastic to listen and actively ask when given the opportunity for discussion. The results of the health education evaluation showed that the elderly were able to mention and explain again the importance of maintaining health.

CONCLUSION. Community service activities carried out by lecturers, and students to the elderly can be declared successful. Through the results of the evaluation during health education took place namely the existence of a positive response from the elderly and also able to mention again about the material that has been presented.

Keywords: Health Education, Elderly, Exercise

\section{PENDAHULUAN}

Berdasarkan pengertian lanjut usia secara umum, seseorang dikatakan lanjut usia (lansia) apabila usianya 65 tahun keatas ${ }^{1}$. Usia lanjut adalah sesuatu yang harus diterima sebagai suatu kenyataan dan fenomena biologis. Kehidupan itu akan diakhiri dengan proses penuaan yang berakhir dengan kematian².

Menurut World Health Organization (2017), di kawasan Asia Tenggara populasi Lansia sebesar $8 \%$ atau sekitar
142 juta dan akan terus meningkat setiap tahunnya ${ }^{3}$. Sedangkan, menurut data Badan Pusat Statistik (BPS, 2017) menunjukkan bahwa pada tahun 2017 terdapat 23,66 juta jiwa penduduk lansia di Indonesia (9,03\%). Jumlah lansia di Provinsi Kalimantan Tengah mencapai 13.202.280 jiwa. Jumlah lansia di Kota Palangka Raya 11.701 jiwa $^{4}$.

Diantara perubahan-perubahan yang terjadi pada lansia, hampir $80 \%$ lansia mengalami perubahan fisik yang bersifat kronis dan mengganggu mobilitas serta 
Putria Carolina, Yelstria Ulina Tarigan, Bella Novita, Desi Indrini, Efriadi, Enteng Pandi Yangan, Mendi, dan Marsiane Afiana

kemandirian lansia ${ }^{5}$. Perubahan fisik yang paling sering terjadi pada lansia adalah pada sistem muskuloskeletal, dimana terjadi perubahan pada kolagen yang merupakan penyebab turunnya fleksibilitas pada lansia dan menimbulkan dampak berupa nyeri dan penurunan kemampuan otot sehingga lansia mengalami hambatan dalam melakukan aktivitas sehari-hari ${ }^{6}$.

Penuaan adalah proses biologis normal pada manusia meliputi perubahan yang berangsur-angsur, mulai dari struktur, fungsi, dan toleransi tubuh terhadap stress lingkungan. Efektifitas berbagai fungsi sisiologik tubuh akan mulai menurun pada usia 30-an dan akan terlihat semakin jelas pada usia 55-60 tahun. Semakin bertambahnya usia, fungsi organ tubuh akan semakin menurun baik karena faktor alamiah maupun karena penyakit, hal tersebut tentunya berdampak pada berbagai aspek kehidupan, baik sosial, ekonomi, dan kesehatan. Permasalahan lanjut usia harus menjadi perhatian dari semua pihak, baik pemerintah, lembaga masyarakat, dan masyarakat itu sendiri.

Lansia di Indonesia tidak semuanya dapat melakukan olahraga, karena terhambat berbagai keterbatasan. Di samping itu jumlah lansia yang setiap dua tahunnya mengalami peningkatan memerlukan pelayanan yang lebih baik, terutama dari keluarga maupun pemerintah. Latihan olahraga bagi lansia bertujuan untuk meningkatkan kebugaran jasmani. Untuk memperoleh kebugaran jasmani yang baik, harus melatih semua komponen dasar kebugaran jasmani yang meliputi ketahanan jantung, peredaran darah dan pernapasan, ketahanan otot, kekuatan otot serta kelenturan tubuh. Dengan adanya proses penuaan menyebabkan adanya kemunduran prestasi kerja dan penurunan kapasitas fisik seseorang, untuk mempertahankan agar kondisi kebugaran jasmani maka diperlukan olahraga. Aktifitas fisik atau olahraga merupakan media terbuka yang dapat dimanfaatkan oleh lansia sesuai dengan kemampuan, kesenangan, tujuan dan kesempatan yang dimiliki oleh setiap orang. Latihan olahraga pada lansia harus disesuaikan dengan kemampuan individu masing-masing berdasarkan kemampuan fisik, kebutuhan, dan tujuan melakukan aktivitas olahraga tersebut.

Salah satu peran perawat dalam upaya preventif yang dilakukan untuk meminimalisir permasalahan khusus pada lansia adalah dengan tetap menjaga pola hidup aktif melalui olahraga. Olahraga yang dilakukan dengan aturan yang sesuai akan memberikan manfaat bagi lansia salah satunya adalah menjaga tingkat kebugaran jasmani tetap baik sesuai dengan usia.

\section{METODE PENGABDIAN MASYARAKAT}

Metode pelaksanaan kegiatan pengabdian masyatakat yang dilakukan adalah melalui pendidikan kesehatan yang diberikan pada lansia di Posyandu Eka 
Pengabdian Masyarakat Pendidikan Kesehatan Menjaga Kesehatan Dan Kebugaran Melalui Olahraga Bagi Lansia Di Posyandu Eka Harapan Kelurahan Pahandut Palangka

Raya

Harapan Kelurahan Pahandut Palangka Raya. Kegiatan ini dilakukan pada bulan November tahun 2018.

Tujuan pelaksanaan kegiatan ini adalah menjadikan kesehatan sebagai sesuatu yang bernilai di masyarakat khususnya lansia, mengarahkan cara-cara hidup sehat menjadi kebiasaan hidup sehari-hari, menolong individu agar mampu secara mandiri mengadakan kegiatan untuk mencapai tujuan hidup sehat.

Sasaran primer dari kegiatan ini adalah lansia, yang merupakan anggota dalam keluarga. Guna mencapai perilaku sehat dalam keluarga, maka harus dimulai pada individu. Sasaran sekunder adalah para kader Posyandu Lansia Eka Harapan Kelurahan Pahandut Palangka Raya.

Ruang lingkup kegiatan ini adalah pada upaya peningkatan kesehatan melalui kegiatan preventif dan promotif yaitu pelayanan bagi lansia yang sehat, agar tetap sehat dan bahkan meningkat status kesehatannya.

Metode pendidikan kesehatan yang digunakan adalah dengan ceramah dan tanya jawab. Media yang digunakan adalah dengan LCD proyektor dan leaflet yang dibagikan kepada lansia yang mengikuti pendidikan kesehatan. Pelaksana kegiatan pendidikan kesehatan adalah tim pengabdian masyarakat dari STIKes Eka Harap yang terdiri dari edukator, fasilitatitor, observer, notulis, dokumentator.

\section{HASIL DAN PEMBAHASAN}

Kegiatan pengabdian masyarakat ini dilakukan sebagai kontribusi institusi pendidikan dalam upaya turut serta meningkatkan derajat kesehatan masyarakat khususnya bagi Lansia lansia di Posyandu Eka Harapan Kelurahan Pahandut Palangka Raya.

Kegiatan yang dilakukan oleh tim pengabdian masyarakat berjalan dengan baik dan mendapat respon yang positif dari lansia. Lansia yang hadir dalam kegiatan pendidikan kesehatan adalah sebanyak 26 orang.

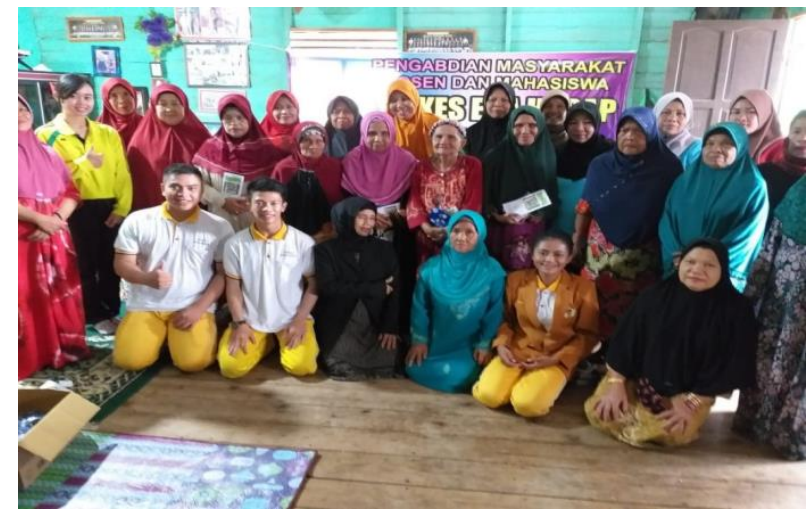

Gambar 1 Foto bersama para lansia

Edukasi yang diberikan pada kegiatan pendidikan kesehatan ini mengenai pentingnya menjaga kesehatan dan kebugaran melalui olah raga.

Tahap kegiatan yang dilakukan oleh tim dengan masing-masing tugasnya adalah sebagai berikut:

1. Kegiatan pertama yang dilakukan oleh edukator adalah membuka kegiatan 
Putria Carolina, Yelstria Ulina Tarigan, Bella Novita, Desi Indrini, Efriadi, Enteng Pandi Yangan, Mendi, dan Marsiane Afiana

dengan memberikan salam pembuka, memperkenalkan diri dan tim, menyampaikan maksud dan tujuan kegiatan pendidikan kesehatan dan melakukan kontrak waktu dengan peserta.

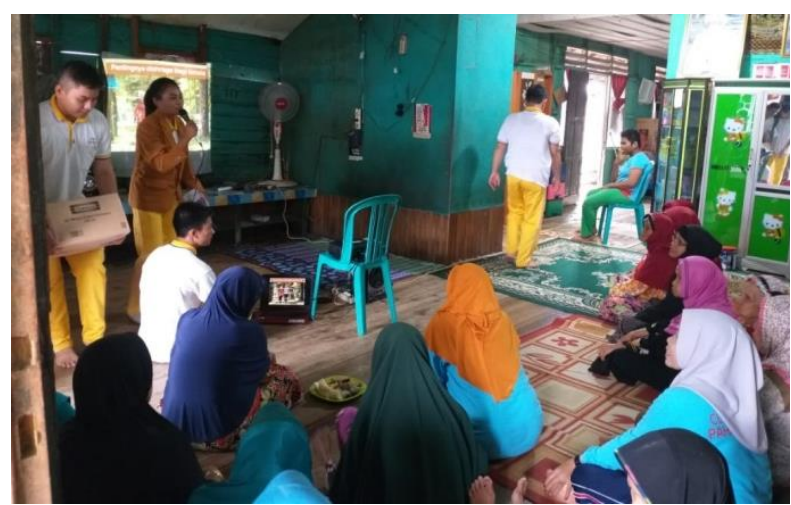

Gambar 2. Kegiatan Pembukaan

2. Selanjutnya edukator menyajikan materi pendidikan kesehatan dengan metode memberikan ceramah selama 30 menit kepada lansia. Media yang digunakan oleh edukator selama menyajikan materi adalah dengan LCD Proyektor. Posisi edukator berada di depan menghadap keluarga yang hadir, sesekali berjalan mendekati barisan duduk peserta.

3. Setelah edukator selesai menyajikan materi, selanjutnya adalah sesi tanya jawab dan diskusi selama 30 menit. Selama kegiatan diskusi berlangsung, fasilitator sangat berperan aktif untuk merangsang peserta agar aktif bertanya mengenai topik yang sedang dibahas. Selama kegiatan berlangsung fasilitator duduk menyebar bersama dengan peserta kegiatan. Peserta sangat antusias dengan materi yang diberikan, mereka mengungkapkan sangat bermanfaat karena sebelumnya belum pernah mendapatkan informasi serupa.

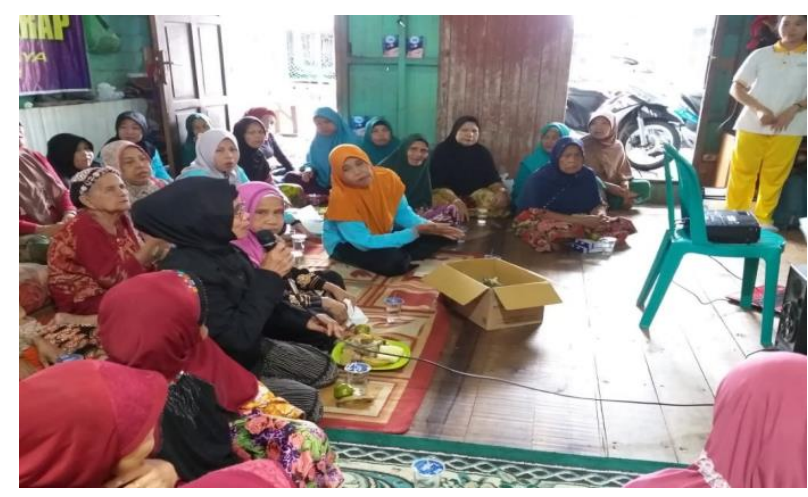

Gambar 3. Sesi Diskusi

Setelah menyajikan materi, dilanjutkan dengan pelaksanaan olah raga bersama lansia. Olah raga kebugaran yang dilakukan merupakan senam khusus bagi lansia untuk menjaga kesehatan dan kebugaran.

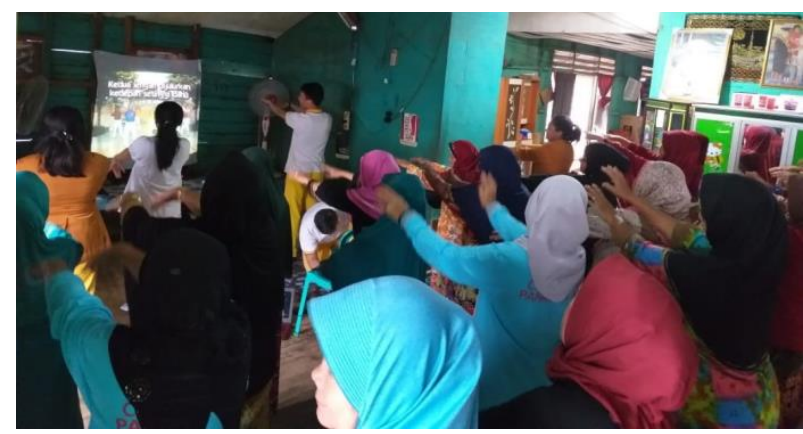

Gambar 4. Olah raga untuk kebugaran lansia

4. Sesi akhir dari kegiatan adalah feed back yang diberikan oleh edukator. Memberikan apresiasi kepada peserta karena telah mengikuti kegiatan dengan tertib dan antusias untuk bertanya. 
Pengabdian Masyarakat Pendidikan Kesehatan Menjaga Kesehatan Dan Kebugaran Melalui Olahraga Bagi Lansia Di Posyandu Eka Harapan Kelurahan Pahandut Palangka

Raya

5. Selama kegiatan berlangsung, dua aspek yaitu aspek positif dan negatif. observer memiliki tugas untuk melakukan pengamatan terhadap jalannya kegiatan dan mencatatnya. Notulis melaksanakan kegiatan pencatatan kejadian-kejadian yang berlangsung yaitu bagaimana peran dari tim, peserta dan lingkungan sekitar. Sedangkan dokumentator adalah melakukan dokumentasi selama kegiatan berlangsung dengan media kamera.

6. Kegiatan terakhir adalah penutup, edukator menutup kegiatan.

\section{Pengetahuan adalah hasil} penginderaan manusia, atau hasil tahu seseorang terhadap objek melalui indera yang dimilikinya (mata, hidung, telinga dan sebagainya). Dengan sendirinya pada waktu penginderaan sampai menghasilkan pengetahuan tersebut sangat dipengaruhi oleh intensitas perhatian dan persepsi terhadap objek. Sebagian besar pengetahuan seseorang diperoleh melalui indera pendengaran (telinga), dan indera penglihatan (mata). Pengetahuan seseorang terhadap objek mempunyai intensitas atau tingkat yang berbeda-beda 7].

Peningkatan pengetahuan tidak mutlak diperoleh di pendidikan formal, akan tetapi juga dapat diperoleh pada pendidikan nonformal. Pengetahuan seseorang tentang sesuatu objek juga mengandung

Kedua aspek inilah yang akhirnya akan menentukan sikap seseorang terhadap objek tertentu. Semakin banyak aspek positif dari objek yang diketahui, maka akan menumbuhkan sikap makin positif terhadap objek tersebut.

Informasi merupakan sesuatu yang dapat diketahui oleh seseorang untuk meningkatkan pengetahuan, namun ada pula yang menekankan informasi sebagai transfer pengetahuan. Selain itu, informasi juga dapat didefinisikan sebagai suatu teknik untuk mengumpulkan, menyiapkan, menyimpan, memanipulasi, mengumumkan, menganalisis, dan menyebarkan informasi dengan tujuan tertentu.

Informasi yang diperoleh baik dari pendidikan formal maupun nonformal dapat memberikan pengaruh jangka pendek (immediate impact) sehingga menghasilkan perubahan atau peningkatan pengetahuan. Berkembangnya teknologi akan menyediakan bermacam-macam media massa yang dapat memengaruhi pengetahuan masyarakat tentang inovasi baru. Dalam penyampaian informasi sebagai tugas pokoknya, media massa juga membawa pesan-pesan yang berisi sugesti yang dapat mengarahkan opini seseorang. Adanya informasi baru mengenai sesuatu hal memberikan landasan kognitif baru bagi terbentuknya pengetahuan terhadap hal tersebut. 
Putria Carolina, Yelstria Ulina Tarigan, Bella Novita, Desi Indrini, Efriadi, Enteng Pandi Yangan, Mendi, dan Marsiane Afiana

Hidup sehat sangat didambakan oleh semua orang karena bila kesehatannya terganggu akan berakibat pada dirinya sendiri. Kesehatan merupakan sumber kesenangan, kenikmatan dan kebahagiaan. Oleh karena itu sangat bijaksana bila kesehatan pribadi selalu dipelihara dan ditingkatkan.

Melalui kegiatan pendidikan kesehatan yang dilakukan pada kelompok lansia di Posyandu Eka Harapan Keluaragan Pahandut Palangka Raya diharapkan akan memberikan dampak positif untuk perubahan pola hidup para lansia ke aras yang lebih baik. Pola hidup sehat yaitu segala upaya unuk menerapkan kebiasaan yang baik dalam menciptakan hidup yang sehat dan menghindari kebiasaan buruk yang dapat menggangu kesehatan. Adapun faktor-faktor yang mempengaruhi pola hidup sehat yaitu: pola kebersihan diri, pola makanan dan minuman yang sehat, ola gerak badan atau olahraga, pola keseimbangan kegiatan, pola pencegahan dan kesehatan diri.

\section{KESIMPULAN}

Hasil pengabdian masyarakat ini dapat menjadi sumber informasi bagi petugas kesehatan terutama perawat dalam memberikan asuhan keperawatan pada tatanan komunitas dengan sasaran lansia. Sebaiknya kegiatan ini dilakukan secara rutin oleh petugas kesehatan sebagai tindak lanjut bagi masyarakat dalam rangka meningkatkan derajat kesehatan yang optimal.

\section{DAFTAR PUSTAKA}

1. Effendi, F \& Makhfudli. 2009. Keperawatan Kesehatan Komunitas: Teori dan Praktek Dalam Keperawatan. Jakarta: Salemba Medika.

2. Hutapea. 2015. Asuhan Keperawatan Lansia, Jakarta: Trans Info Medika.

3. WHO. 2017. The Global Burden Of Disease 2017 Update. Switzerland: WHO Press.

4. Badan Pusat Statistik RI. 2017. Sensus Penduduk Tahun 2017. Jakarta: Badan Pusat Statistik RI.

5. Potter \& Perry. 2005. Buku Ajar Keperawatan Fundamental Keperawatan. Jakarta: Penerbit Buku Kedokteran EGC.

6. Azizah, Lilik M. 2011. Perawatan Lanjut Usia. Surabaya: Graha IImu.

7. Notoatmodjo, Soekidjo. 2010. Promosi Kesehatan dan IImu Perilaku, Edisi Revisi. Jakarta: Rineka Cipta. 